\title{
A Conjoint Analysis of Propellant Budget and Maneuver Life for a Communication Satellite
}

\author{
İbrahim ÖZ ${ }^{1}$ \\ ${ }^{1}$ Corresponding Author; Turksat AS, Cevizlidere Cad. No:31 Ankara/Turkey; ioz@turksat.com.tr; \\ +903129252000
}

Received 23 December 2020; Revised 2 February 2021; Accepted 17 February 2021; Published online 25 February 2021

\begin{abstract}
Maneuvers require velocity augmentation to control a satellite at the defined orbit. The velocity augmentation provides achieving geostationary orbit, compensating orbital perturbation, orbit dispersion correction, and any other maneuver's operations for a communication satellite. All maneuvers and propellant consumption must be taken into account in the propellant budget for successful mission management. In this study, a straightforward method was proposed to calculate satellite maneuver life or associated propellant budget for general purposes. The method provides enough accuracy for general mission planning. However, communication satellite accurate end of life estimation, especially in the last three months is vitally important and depends on many factors. According to the performance requirement of procurement's standard, the propellant budget and associated satellite maneuver's life are calculated based on the worst-case or adverse three-sigma. The worst-case calculations include allocations for inefficiencies, velocity uncertainties, dispersions resulting from thruster firings, propellant residuals, the selected thrusting, and maneuver strategies' performance. High accuracy remaining propellant estimation is necessary for a successful end of life operation and decommissioning. The cost of early deorbit because of propellant misestimation is millions of dollars. Accurate remaining propellant and associated maneuver life analysis can be performed in different methods.

The most common three methods are pressure, volume, temperature (PVT), bookkeeping (BK), and thermal propellant gauging (TPG). The propellant accuracy analysis shows that the propagation of uncertainties is related to system design, tank fill ratio, propellant load accuracy, orbital maneuver's inefficiency, pressure and temperature sensors, transducers, telemetry resolution, and error in equipment test data. Comparing the methods, PVT provides accuracy between $\pm 27.81 \mathrm{~kg}$ to $\pm 38.93 \mathrm{~kg}$, depending on equipment size and accuracy. BK currently provides the best estimation and the highest gauging accuracy between $\pm 9.83 \mathrm{~kg}$ to $\pm 13.76 \mathrm{~kg}$. TPG provides accuracy between \pm 10.52 to $\pm 14.73 \mathrm{~kg}$ for some cases. However, the satellite operators request $\pm 1 \mathrm{~kg}$ estimation of the remaining propellant to extend the lifetime and reduce costs. The satellite manufacturers should optimize propulsion and attitude control subsystem design and manufacturing, including propellant management device performance, applied sensors reliability and accuracy, and tank expansion performance over a mission life.
\end{abstract}

Keywords: satellite maneuver life, propellant budget, pvt, bookkeeping, pulse counting, thermal gauging

\section{Introduction}

The satellite operators maneuver the satellites to control them at the desired orbit by changing their velocity. The velocity changes require force to apply to the satellites. Applying force is possible by using the thrusters. The thrusters need a propellant (fuel and oxidizer) to generate a force. Satellite fuel and oxidizer tanks are loaded according to mission requirements and the capability of the propulsion system. The satellites consume the fuel and oxidizer starting from transfer orbit operations. The propellant consumption continues with the geosynchronous orbit (GEO) operations and finishes with a de-orbit operation. Satellite design life and service life are not significant factors to estimate in orbit operation duration. The fuel is a crucial factor to determine a satellite life in space. Theoretical maneuver life can be computed using the classical Tsiolkovsky rocket equation. However, maneuver life parameters have uncertainties. More accurate maneuver calculations become very complicated by considering uncertainties associated with the different error sources. The satellite end of life is calculated by estimation of remaining fuel after each usage. The fuel estimation algorithms/methods provide the remaining fuel in the onboard propellant tank(s) [1]. 
Currently, there are three common propellant gauging methods in use. Those are pressure, volume, temperature (PVT), ideal gas law, Bookkeeping (BK), propellant flow integration, and thermal propellant gauging (TPG).

The PVT method relies on the ideal gas law PV=nRT. The tanks' pressure and temperature data are received via telemetry, and then the propellant volume and mass are obtained from pressuring gas (Helium) volume. The method's accuracy depends on the pressure transducer's accuracy, telemetry data resolution, and tank fill ratio. The accuracy decreases when the propellant amount decreases, but there is no accumulative error [2]. The accuracy of PVT depends on equipment measurement accuracy precision and size of the tanks.

The BK, bookkeeping (or pulse counting) method is based on thruster flow rate prediction. In this method, all thrusters on-times, pulse widths, and flow rates are recorded. The uncertainty of the flow rate during apogee kick engine (AKE) and thruster firings affect the method's accuracy directly. The propellant flow rate depends on many parameters like thruster temperature, feed-pressure, and dutycycle. The BK method has a typically consumed propellant accuracy in between $\pm 0.5 \%$ and $3.5 \%$. Thrusters parameters and efficiency of firing mode (pulse or continues) may have different values; however, these values are taken as constant. An accumulated error occurs when time increases [5].

The TPG (thermal propellant gauging) method relies on the tank's thermal response filled with liquid propellant and pressuring gas helium. In the TPG test, the resulting temperature increase with time due to the known amount of energy applied to the propellant tank by the heaters, are recorded. Temperature versus heating time curves for different propellants are utilized to calculate in orbit propellant estimation using on-orbit TPG data. The TPG method is superior to the Bookkeeping and PVT methods [3]. The accuracy of the Bookkeeping and the PVT methods decrease due to an accumulation of error with time. The TPG method has increasing accuracy with time [3]. However, in the ABS-1A case, the TPG method provided the best result. The remaining propellant has been predicted for PVT, BK, and TPG. The satellite has been decommissioned, and all tanks fully depleted. The actual tank remaining propellant is estimated, and the methods are compared. The results showed that TPG prediction was very accurate and less than $1 \mathrm{~kg}$. In case of a pressure transducer failure, PVT and BK methods become unavailable, but the TPG can provide data about the remaining fuel. It is an additional capability for propellant estimation. [4]. TPG method propellant error estimation is inversely proportional to the heating time [7]. TPG method application on a real in orbit satellite is shown in Figure 1 and Figure 2. Figure 1(a) shows Sat-1 finite element tank model grids developed for TPG.

The development of the finite element model of the propellant tank is a complex process. Figure 1(b) shows temperature distribution over the tank's surface for 20, 50, and 80 hours of heating [7].

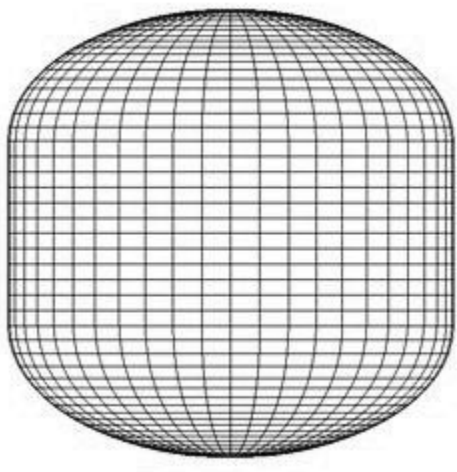

(a)

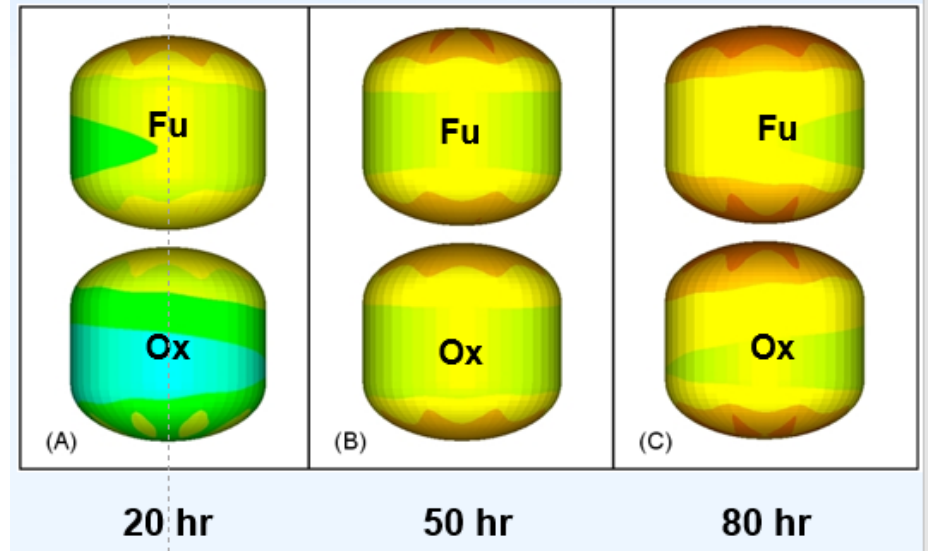

(b)

Figure 1 Sat-1 tank thermal model (a) Finite Element model (b) temperature distribution 
Figure 2(a) shows the remaining fuel estimation based on simulation results. The solid line shows simulation results, and markers show flight data temperature sensor readings. Tank heaters were turned $\mathrm{ON}$ at $\mathrm{t}=0$. Figure 2 (b) shows TPG operations, response to heaters. The temperature versus time data of top and bottom oxidizer and fuel tanks. Figure 2 (a) curves were obtained using TPG test data and their several times' calculated simulation results.

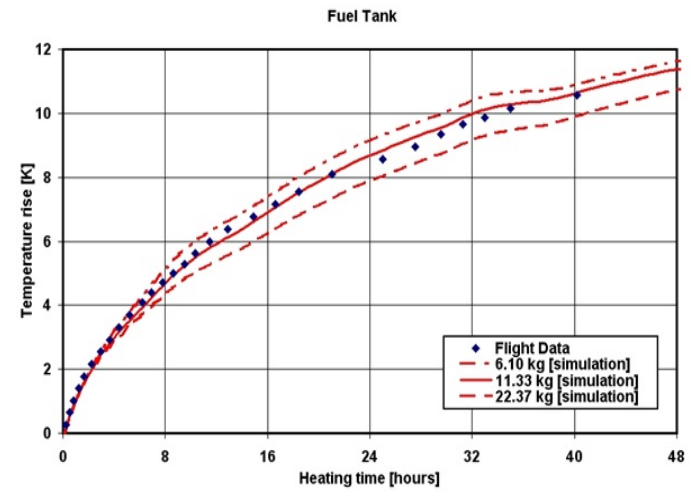

(a)

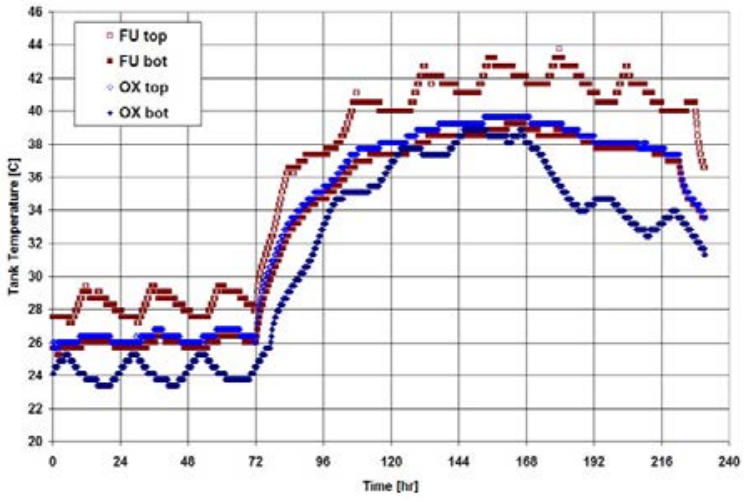

(b)

Figure 2 (a) Results of TPG estimation for fuel tanks. (b) TPG operations, response to heater.

All three-gauging methods have differences between them. System design and types of equipment highly affect the precision of the gauging systems.

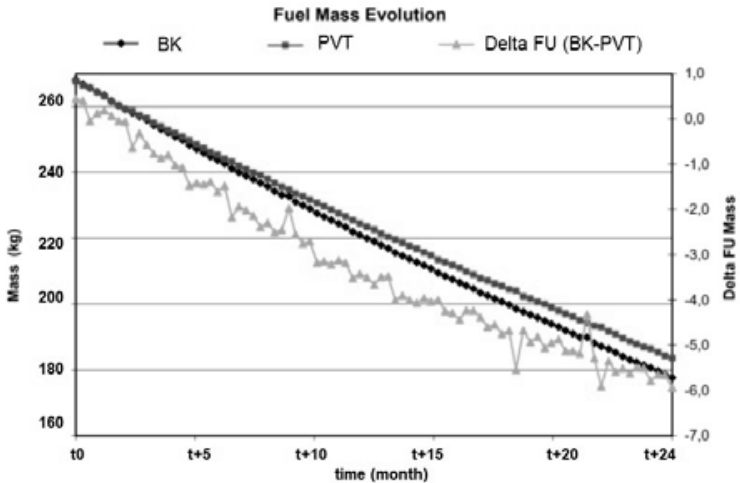

(a)

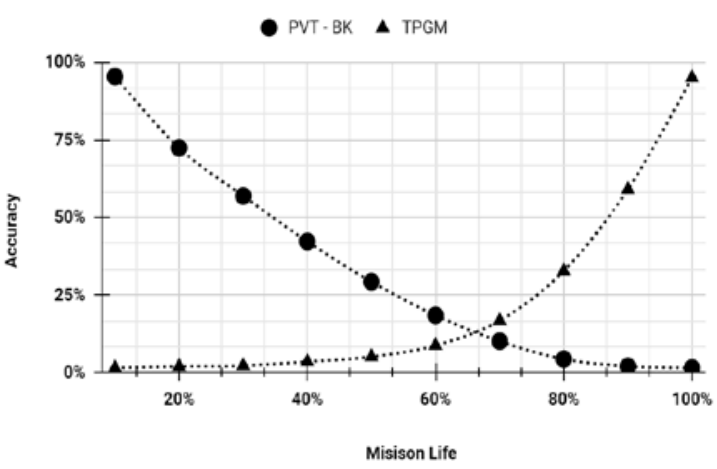

(b)

Figure 3 (a) PVT and BK comparison with in-orbit data (b) Schematic representation of propellant gauging systems error built-up

Figure 3(a) shows PVT vs. BK fuel evaluation of Sat-A in-orbit data. The remaining propellant was calculated after each use. The difference between BK and PVT methods are shown on the left vertical axis.

Figure 3 (b) shows the general trend of PVT-BK versus the TPG method for estimation of remaining propellant performance. The PVT and BK have better accuracy than the TPG method at the beginning of satellite life. The accuracies of all methods are comparable in the middle of life. However, the TPG method has better accuracy than PVT and BK at the end of satellite life.

Table 1 provides currently available the most popular propellant gauging system, their description, and sensors [1]. The sensor's accuracy is a major contributor to propellant gauging and calculations. 
Ibrahim $\mathrm{Oz}$

Table 1 Typical parameters and sensors for three gauging systems

\begin{tabular}{|l|l|l|}
\hline Method & \multicolumn{1}{|c|}{ Description } & \multicolumn{1}{|c|}{ Sensors } \\
\hline PVT & $\begin{array}{l}\text { Pressure, volume, temperature (gas law) based on } \\
\text { measurement of absolute pressure and temperature. }\end{array}$ & $\begin{array}{l}\text { pressure transducers, temperature } \\
\text { sensors }\end{array}$ \\
\hline BK & $\begin{array}{l}\text { Bookkeeping, based on counting firings and flow of } \\
\text { propellant. }\end{array}$ & $\begin{array}{l}\text { thrust, flow-meter, temperature } \\
\text { sensors, pressure sensors, }\end{array}$ \\
\hline TPG & $\begin{array}{l}\text { Thermal propellant gauging; based on the measurement of } \\
\text { the temperature response of the fuel tank after applying heat } \\
\text { via tank heaters. }\end{array}$ & $\begin{array}{l}\text { temperature sensors, power } \\
\text { measurements }\end{array}$ \\
\hline
\end{tabular}

Commercial communication satellite's replacement is very expensive and puts pressure on the improvement of end-of-life gauging accuracy for lifetime extension. The communication satellite lifetime can be extended by performing only the east-west station-keeping (EWSK) maneuver to use the remaining limited amount of fuel more efficiently. The satellite operators decide to stop the north-south station-keeping (NSSK) maneuvers of a communication satellite to extend the lifetime for several years. In this case, satellites become operated in an inclined geosynchronous orbit (IGSO), and only EWSK maneuvers are performed. EWSK maneuver consumes much less propellant than NSSK maneuvers. It is about 20-24 times less propellant consumption than NSSK maneuvers [8]. The satellite operators may provide special services and protect their orbital rights with few amounts of fuel in inclined geosynchronous orbit (IGSO) for many years. In this case, a small amount of propellant becomes very important and may lead to saving millions of dollars. A few amounts of uncertainty in the fuel may correspond to several years of in-orbit operations with high revenues [9]. The problem of the estimation of remaining propellant on geo satellites is a nightmare for the manufacturer and the operators. Early deorbit of a satellite because of misestimation causes a huge commercial loss. In general, the manufacturer prefers the worst-case end of life approach to deorbit the satellite and have a new satellite order while the satellite operators try to continue operation as long as possible. Early deorbit of a satellite not only causes the revenue loss in inclined services but also may cause to rent an interim satellite to protect orbital rights. The cost of orbital rights protection is a million of dollars debate.

Various satellite operators have different regulations, priority, and approaches to satellite end of life topics. Some operators never perform a deorbit maneuver and use every drop of propellant for nominal maneuvers, but ITU-R recommends moving the satellite graveyard. As a result, the process to obtain common decisions is long and complicated [9].

The satellite operators are crucial to have accurate propellant gauging systems onboard communication satellites for cost-effective decommissioning. However, currently, the best gauging systems in use typically have an End-of-life (EOL) prediction of \pm 4-6 months for a geostationary satellite because of a combination of sensor accuracies, design, and cost limitations. In order to guarantee a 20-30 year of continuous operation, satellite builders usually take appropriate margins in the amount of propellant onboard. EOL accuracy is typically in between \pm 3 to \pm 15 months, depending on the gauging method and satellite system's parameters currently. More precise monitoring of the remaining propellant could extend the operational life of a satellite. The improvement of gauging accuracy is linked with the system design, and sensor accuracies. A precise comparison of all gauging methods is hard to perform [3], [10].

Tank volume and pressure variation uncertainty considerably impact the compressed propellant mass gauging. Tank volume error increases with a higher fill ratio, but in contrast, pressure variation error decreases with a high fill ratio [11]. The gauging methods have different error characteristics of prediction data due to the calculation method principle. The uncertainty of each measurement method should be estimated based on this approach [13]. The remaining propellant quantity is highly sensitive to the propellant tank pressure sensor and pressurant tank temperature sensor. This error causes a residual (ullage) amount over-prediction in the tank in general [14]. 


\section{Straightforward Maneuver Life Calculation Methods}

The propellant budgets are calculated according to mission requirements and associated maneuver life. The satellites need velocity change during their mission life. This velocity change $(\Delta \mathrm{V})$ can be achieved by using thrusters. The spacecraft life cycle $\Delta \mathrm{V}_{\text {Total }}$ can be expressed in the following Equation 1 ,

$$
\Delta \mathrm{v}_{\text {Total }}=\Delta \mathrm{v}_{\mathrm{GTO}-\mathrm{to}-\mathrm{GEO}}+\Delta \mathrm{v}_{\mathrm{NSSK}}+\Delta \mathrm{v}_{\mathrm{EWSK}}+\Delta \mathrm{v}_{\mathrm{AOCS}}+\Delta \mathrm{v}_{\mathrm{re}-\mathrm{loc}}+\Delta \mathrm{v}_{\text {disp }}+\Delta \mathrm{v}_{\text {de-orbit }}
$$

where:

$\Delta \mathrm{V}_{\text {GTO-to-GEO }}$ necessary velocity augmentation to rise from geo transfer orbit (GTO) to GEO m/s, $\Delta \mathrm{V}_{\text {NSSK }}$ north-south station keeping velocity augmentation $\mathrm{m} / \mathrm{s}$,

$\Delta \mathrm{V}_{\text {EWSK }}$ east-west station keeping velocity augmentation $\mathrm{m} / \mathrm{s}$,

$\Delta \mathrm{V}_{\text {AOCs }}$ attitude control velocity augmentation $\mathrm{m} / \mathrm{s}$,

$\Delta \mathrm{V}_{\text {re-loc }}$ station relocation velocity augmentation $\mathrm{m} / \mathrm{s}$,

$\Delta \mathrm{V}_{\text {disp }}$ dispersion of launcher, AKE and thrusters,

$\Delta \mathrm{V}_{\text {de-orbit }}$ maneuver to rise orbit to graveyard velocity augmentation $\mathrm{m} / \mathrm{s}$.

Each $\Delta \mathrm{V}$ of Equation 1 can be calculated or estimated in different methods. The first term $\Delta \mathrm{V}_{\text {GTO-to-GEO }}$ represents the launch and early orbit phase maneuvers. The launch vehicles generally inject the spacecraft into the transfer orbit. Launch vehicle performance and spacecraft mass affect the injected orbit parameters such as semimajor axis, inclination, and eccentricity. The spacecraft needs $\Delta \mathrm{V}$ to climb from transfer orbit to geostationary orbit. The following Equation 2 expresses the necessary $\Delta \mathrm{V}_{\text {GTO-to- }}$ GEO to perform combined inclination change and orbit raising.

$$
\Delta \mathrm{v}_{\mathrm{GTO}-\mathrm{to}-\mathrm{GEO}}=\sqrt{\mathrm{v}_{\mathrm{ap}}^{2}+\mathrm{v}_{\mathrm{GEO}}^{2}-2 \mathrm{v}_{\mathrm{ap}} \mathrm{v}_{\mathrm{GEO}} \cos \Delta \mathrm{i}}
$$

where; $\mathrm{v}_{\mathrm{ap}}$, velocity at apogee $\mathrm{m} / \mathrm{s}, \mathrm{v}_{\mathrm{GEO}}$, velocity at GEO $\mathrm{m} / \mathrm{s}$, and $\Delta \mathrm{i}$ inclination angle change

Table 2 provides information about currently available the most common commercial launch vehicle performance and necessary $\Delta \mathrm{V}_{\mathrm{GTO} \text {-to-GEO }}$ for a satellite to reach the final geostationary orbit. The results were obtained by using Equation 2.

Table 2 launch vehicle's typical performance and necessary $\Delta \mathrm{V}$ to rise orbit from GTO to GEO

\begin{tabular}{|c|c|c|c|c|}
\hline Launcher & Inclination (deg) & Perigee (km) & Apogee (km) & $\Delta$ V to geo (m/s) \\
\hline Falcon-9 & 28.5 & 185 & 35786 & 1837.45 \\
\hline Ariane-5 & 6.0 & 250 & 35786 & 1490.27 \\
\hline Ariane-5 & 2.0 & 250 & 35786 & 1470.10 \\
\hline Proton & 12.0 & 9800 & 35786 & 961.15 \\
\hline
\end{tabular}

The satellites in orbit are under perturbing forces such as the sun, the moon, the non-uniform gravitational force of the earth, and solar pressure, etc. The satellite oscillates in a north-south direction and drifts in the east or west direction due to these forces. The satellite operators perform north-south station-keeping (NSSK) and east-west station-keeping (EWSK) maneuvers regularly to compensate for the perturbation in orbit. Figure 3(a) shows annual inclination increment and necessary $\Delta \mathrm{V}_{\mathrm{NssK}}$ starting from 2020 for 30 years [8]. It is seen that the $\Delta V$ requirement varies with time. The EWSK maneuver $\Delta \mathrm{V}_{\text {EWSK }}$ requirement depends on mainly the orbital slot of a satellite as shown in figure 3b [15], [16]. 


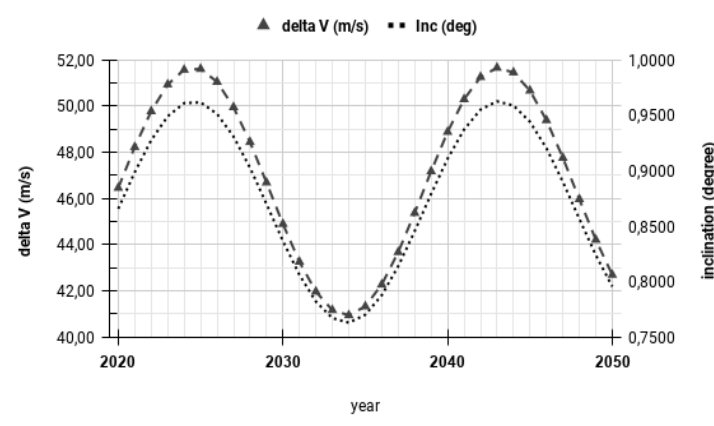

(a)

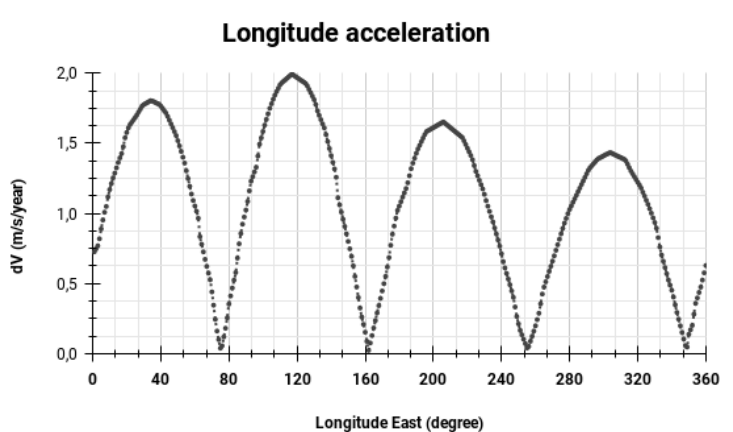

(b)

Figure 4 (a) Annual $\Delta \mathrm{V}$ of GEO satellite for NSSK (b) Annual $\Delta \mathrm{V}$ of GEO satellite for EWSSK

Satellite $\Delta \mathrm{V}$ capacity identifies the maneuver life of a satellite. Satellite dry mass and on-board loaded propellants and thrusters' specific impulses are key factors to amount off $\Delta \mathrm{V}$. The Tsilknovksy rocket equation provides an amount of $\Delta \mathrm{V}$ value from the given parameters (satellite wet mass $\mathrm{m}_{0}$ and dry mass $\mathrm{m}_{1}$ ) as shown in Equation 3.

$$
\Delta \mathrm{v}=\mathrm{I}_{\mathrm{sp}} \mathrm{g}_{0} \ln \left(\frac{\mathrm{m}_{\mathrm{o}}}{\mathrm{m}_{1}}\right)
$$

Satellite mass change for the required $\Delta \mathrm{V}$ can be calculated by using the following Equation 4 derived from Equation 3.

$$
\mathrm{m}_{1}=\mathrm{m}_{0} \mathrm{e}^{\frac{-\Delta \mathrm{v}}{\mathrm{I}_{\mathrm{sp}} \mathrm{g}_{0} \eta}}
$$

where; $\mathrm{m}$ : satellite mass before the maneuver, $\mathrm{I}_{\mathrm{sp}}$ : specific impulse of the thruster(s) used

$\eta$ : maneuver efficiency, $\Delta \mathrm{V}$ : velocity increment.

Satellite maneuver lifetime can be computed by using Equation 1. Total $\Delta \mathrm{V}$ requirement can be calculated by satellite propellant budget analysis. The primary parameters and conditions to execute propellant budget analysis are the following items; launch date, based on the worst-case or adverse threesigma performance from the thrusters' datasheet, satellite dry mass, thruster efficiencies (e.g., thruster canting and plume impingement), other inefficiencies in propellant residuals, velocity uncertainties and dispersions resulting from thruster firings. The $\Delta \mathrm{V}$ requirements come from orbital mechanics. GEO orbit insertion, NSSK, and EWSK, and propellant budget approach identify the usage of $\Delta \mathrm{V}$ and associated propellant.

Velocity change $(\Delta \mathrm{V})$ optimization is necessary for all maneuvers. $\Delta \mathrm{V}_{\mathrm{GTO} \text {-to-GEO }}$ should be optimized with respect to the launcher and apogee kick engine (AKE) performances, depending on the dry mass, filling ratio, and level of confidence to be reached in orbit insertion. This $\Delta \mathrm{V}$ is provided by the $400 \mathrm{~N}$ AKE (sometimes called apogee boost motor ABM or liquid apogee engine LAE). The total $\Delta$ Vgto-togeo requirement is the nominal $\Delta \mathrm{V}$ for raising the perigee to GEO altitude from transfer orbit perigee altitude while also removing transfer orbit inclination. $\Delta \mathrm{V}_{\text {GTO-to-GEO }}$ is $1470.1 \mathrm{~m} / \mathrm{s}$ for Ariane $5,250 \mathrm{~km}$ perigee altitude with $2^{\circ}$ inclination.

The cumulative NSSK $\Delta \mathrm{V}$ budget from Figure 2 is $875.84 \mathrm{~m} / \mathrm{s}$ for 20 years from the beginning of January 2020 in the GEO orbit. Similarly, the NSSK $\Delta V$ requirement is $1461.30 \mathrm{~m} / \mathrm{s}$ for 30 years starting from the beginning of January 2020. $\Delta \mathrm{V}_{\mathrm{EWSK}}$ is $1.82 \mathrm{~m} / \mathrm{s} / \mathrm{year}$, averaged between BOL and EOL for when controlled inside a $\pm 0.1^{\circ}$ window at $31^{\circ} \mathrm{E}$ from Figure 4 (b).

Longitude repositioning requires $\Delta \mathrm{V}_{\text {re-loc }}$ equals to.5.7 m/s, corresponding to one longitude shift of $1 \%$ day and End-of-life re-orbiting requires $\Delta \mathrm{V}_{\text {de-orb }}$ equals $12.8 \mathrm{~m} / \mathrm{s}$ to reach the circular graveyard orbit $350 \mathrm{~km}$ above the GEO from Hohman transfer. 
The propellant mass requirements for attitude control and wheel unloading is $3 \mathrm{~kg}$ for a synchronous GTO injection with three AKE firings. Normal mode and station-keeping mode requires $\Delta \mathrm{V}_{\mathrm{AOCS}}$ equivalent to $0.420 \mathrm{~kg} / \mathrm{year}$, for wheel unloading and attitude control.

Most of these values are based upon typical flight experience and generic analysis of a communication satellite.

Table 3 shows the total $\Delta \mathrm{V}$ for a satellite to operate 30 years in orbit starting from 2020 . It can be recognized that EWSK $\Delta \mathrm{V}_{\text {EWSK }}$ depends on the satellite operational orbital location. Other $\Delta \mathrm{V}$ columns are the sum of attitude control (including wheel unloading), orbital relocation (5.68 m/s for $1^{\circ} /$ day), and de-orbit $\Delta \mathrm{V}_{\text {de-orb }}(12.76 \mathrm{~m} / \mathrm{s}$ for $350 \mathrm{~km})$.

Table 3 Satellites in geosynchronous orbit $\Delta \mathrm{V}$ requirement for 30 and 20 years from 2020 to 2050.

\begin{tabular}{|c|c|c|c|c|c|c|c|c|}
\hline \multirow{2}{*}{ Longitude } & \multicolumn{4}{|c|}{ 30 year lifetime } & \multicolumn{4}{c|}{ 20 year lifetime } \\
\cline { 2 - 9 } & NSSK & EWSK & Others & Total $\Delta$ V m/s & NSSK & EWSK & Others & Total $\Delta$ V m/s \\
\hline $8.5^{\circ} \mathrm{E}$ & 1461.30 & 32.70 & 29.00 & 1523.00 & 975.84 & 18.17 & 24.20 & 1018.21 \\
\hline $31.0^{\circ} \mathrm{E}$ & 1461.30 & 55.20 & 29.00 & 1545.50 & 975.84 & 30.67 & 24.20 & 1030.71 \\
\hline $42.0^{\circ} \mathrm{E}$ & 1461.30 & 53.40 & 29.00 & 1543.70 & 975.84 & 29.67 & 24.20 & 1029.71 \\
\hline $50.0^{\circ} \mathrm{E}$ & 1461.30 & 46.20 & 29.00 & 1536.50 & 975.84 & 25.67 & 24.20 & 1025.71 \\
\hline $75.1^{\circ} \mathrm{E}$ & 1461.30 & 0.00 & 29.00 & 1490.30 & 975.84 & 0.00 & 24.20 & 1000.04 \\
\hline
\end{tabular}

The dispersion budget is calculated based on typical communication satellite analyses and flight experiences. It includes on a worst-case basis (three-sigma) the contributions of launch vehicle dispersions, GEO rising maneuvers dispersions, orbit maneuvers dispersions, attitude control dispersions, mixture ratio dispersions.

Typical thrusters, either for the apogee engine or for the control thrusters, are given in Table 4 . The specific impulses for the AKE and the thrusters have been computed using the qualification test reports. The truster efficiencies are extracted from the datasheet in order to take into account the thrust arc losses.

Table 4 Typical Thrusters specific impulse and efficiency data from manufacturer data sheet

\begin{tabular}{|l|c|c|c|}
\hline Maneuvers & Efficiency (\%) & Isp (sec) & Dispersion (sec) \\
\hline AKE (400N) & 99.6 & 320.7 & \pm 1.1 \\
\hline EWSK (average) & 90.9 & 289.5 & \pm 3.0 \\
\hline NSSK (average) & 93.1 & 287.5 & \pm 3.5 \\
\hline Re-location (MOL) & 90.7 & 288.1 & \pm 3.5 \\
\hline De-orbiting (EOL) & 90.5 & 286.2 & \pm 3.5 \\
\hline Wheel unloading & 90.5 & 286.1 & \pm 3.5 \\
\hline
\end{tabular}

The propellant non-usable quantity includes the static and dynamic residuals, which correspond to nonexpellable propellants due to subsystem design. The static residuals include propellant liquid remaining in lines and propellant liquid and vapor remaining in the tank due to tank expulsion efficiency. Dynamic residuals are due to mixture ratio shifts through satellite life and are mainly influenced by propellant tank temperature and pressure variations. Typically, static residuals are $\pm 0.1 \%$ of consumed propellant, and dynamic residuals are $0.8 \%$ of the propellant consumed mass. Those values highly depend on design and manufacturing parameters; for more accurate data, someone should refer to equipment data sheets and system design parameters from the manufacturers. Concerning loading uncertainty, we assume a typical value of $\pm 0.14 \% \mathrm{~kg}$ of total loaded propellant.

\subsection{Calculation of Uncertainties}

The calculation of uncertainties in the remaining propellant measurement is obtained by the PVT, BK, and TPG methods. As mentioned above, the PVT method is based on the determination, through the use of the on-board pressure and temperature telemetry data, of the remaining liquid volume in the propellants tanks. BK is based on the determination, through the use of the number of pulses, accumulated ON time, and tank pressure telemetry data, of the AKE motor and thrusters consumption. TPG is based on tank thermal response to applied known heater energy. 
The calculation of an error function for three gauging methods is performed based on the volume, pressure, temperature, and power and their relevant sensors precision.

$\beta_{M}$ is defined to analyze the system linearly. The relative system function or the propellant load factor $\beta_{\mathrm{M}}$ is the ratio between the propellant mass and the tank fill mass during assembly, integration, and test (AIT) of a satellite. $\beta_{\mathrm{M}}$ varies over satellite life between $\beta=1$ at AIT and $\beta \sim 0$ at EOL [1]. This ratio is obtained from the system function $f$ as a function of all relevant system parameters $x_{i}$, as shown in Equation 5.

$$
\beta_{\mathrm{M}}=\frac{\mathrm{M}_{\mathrm{L}}}{\mathrm{M}_{\mathrm{AIT}}}=\mathrm{f}\left(\mathrm{x}_{1}, \mathrm{x}_{2}, \mathrm{x}_{3}, \ldots \mathrm{x}_{\mathrm{i}}\right)
$$

In the PVT method, the propellant volume $\mathrm{V}_{\mathrm{L}}$ is estimated from a subtraction of the known tank volume $\mathrm{V}_{\mathrm{T}}$ and the residuals (ullage) volume $\mathrm{V}_{\mathrm{U}}$ using Equation 6.

$$
\mathrm{V}_{\mathrm{T}}=\mathrm{V}_{\mathrm{T}}-\mathrm{V}_{\mathrm{U}}
$$

The propellant mass $M_{L}$ is calculated from propellant density as a function of temperature, as shown in Equation 7.

$$
\mathrm{M}_{\mathrm{L}}=\mathrm{V}_{\mathrm{L}} \rho \mathrm{T}_{\mathrm{L}}=\left(\mathrm{V}_{\mathrm{T}}-\mathrm{V}_{\mathrm{U}}\right) \rho \mathrm{T}_{\mathrm{L}}
$$

So that the EOL gauging accuracy is related to the error in the tank and ullage volume during AIT and the in-flight ullage pressure and temperature sensor accuracies for the PVT method. The momentary propellant mass $M_{\mathrm{L}}$ can be calculated using Equation 8.

$$
\mathrm{M}_{\mathrm{L}}=\mathrm{M}_{\mathrm{AIT}} \beta_{\mathrm{M}}
$$

BK method essential parameters for the propellant system function is the predicted total number of burns $N$ needed for EOL operations to deplete the propellant tank. $N$ is related to the predicted number of burns per day, and the mission duration $D_{m}$ (days), as shown in Equation 9.

$$
\mathrm{N}=\frac{\text { burns }}{\text { day }} \mathrm{D}_{\mathrm{m}}
$$

However, on average, the propellant mass $m_{n}$ expelled per burn for station keeping should be like in Equation 10.

$$
\overline{\mathrm{m}_{\mathrm{n}}}=\frac{\mathrm{M}_{\mathrm{L}, \mathrm{BOL}}}{\mathrm{N}}=\frac{\mathrm{M}_{\mathrm{AIT}}}{\mathrm{N}} \beta_{\mathrm{M}, \mathrm{BOL}}
$$

BK method's EOL gauging accuracy is related to the error in the tank mass during AIT and the relative error of the flow meter per burn, as shown above.

TPG method uncertainty can be calculated as the temperature response as function $T(t)$ when applying a power $(\mathrm{Pe})$ to a propulsion system with heat capacity $\left(H_{S}\right)$, and effective conduction to the satellite $C$ can be calculated with the following differential Equation 11.

$$
\mathrm{P}_{\mathrm{e}}-\mathrm{H}_{\mathrm{s}} \frac{\mathrm{dT}}{\mathrm{dt}}-\mathrm{CdT}=0
$$

The system heat-capacity $H_{S}$, which is the sum of the heat capacity of the propellant $H_{L}$ and the tank $H_{T}$ is estimated from the system temperature response. Equation 12 provides heat response to propellant mass uncertainty.

$$
\frac{\mathrm{P}_{\mathrm{e}}}{\mathrm{C}_{\mathrm{PL}} \mathrm{M}_{\mathrm{L}-\mathrm{AIT}}} \approx \frac{\Delta \mathrm{T}}{\Delta \mathrm{t}} \frac{\mathrm{H}_{\mathrm{s}}}{\mathrm{H}_{\mathrm{L}-\mathrm{AITs}}} \approx \frac{\Delta \mathrm{T}}{\Delta \mathrm{t}} \beta_{\mathrm{M}}
$$

TPG EOL gauging accuracy is related to the error in the tank mass and heat capacity. These two parameters can be measured on the ground. The uncertainty analysis of the TPG method considers two sources, the uncertainty of the curve fit associated with propellant load estimation and uncertainties of specific model parameters. 
Ibrahim $\mathrm{Oz}$

\section{Results and Conclusions}

In this study, we propose a straightforward method to calculate the maneuver life and associated propellant budget. The proposed method uses Equation 1 and calculates the velocity augmentation by using Equation 2 and Equation 3. As an illustrative example, we calculated two satellites' propellant budgets and associated maneuver life. Sat-A has $3500 \mathrm{~kg}$ mass at launch and $1400 \mathrm{~kg}$ dry mass, Sat-B has $4800 \mathrm{~kg}$ launch mass and $1570 \mathrm{~kg}$ dry mass. Assuming both satellites launched on January 1st, 2020, and operated at $31^{\circ} \mathrm{E}$. We follow the steps below to apply the proposed method and calculate the propellant budget of two satellites;

Step 1. Calculate the $\Delta \mathrm{V}$ amount using Equation 3. The result is $2690.70 \mathrm{~m} / \mathrm{s}$.

Step 2. Calculate necessary $\Delta \mathrm{V}$ from GTO to reach GEO by using Equation 2 combine apogee firing and inclination correction (suppose Ariane launch vehicle utilized for launching with $250 \mathrm{~km}$ perigee height and $2^{\circ}$ inclination on January $1 \mathrm{st}, 2020$ ). Necessary $\Delta \mathrm{V}$ is $1470.1 \mathrm{~m} / \mathrm{s}$ to reach geo orbit

Step 3. Calculate satellite mass change because of expelling the propellant by using Equation 4 . The beginning of life at geo satellite mass is calculated as $2129.63 \mathrm{~kg}$ assuming apogee kick engine $\mathrm{I}_{\mathrm{sp}}$ : 321 s and efficiency $99 \%$.

Step 4. Calculate remaining available $\Delta \mathrm{V}$ by using Equation 4 and propellant residuals (ullage), 23.5kg. We obtained $1042.08 \mathrm{~m} / \mathrm{s} \Delta \mathrm{V}$ for operations.

Step 5. Calculate $\Delta \mathrm{V}$ available for NSSK and EWSK. The satellite has $1012.64 \mathrm{~m} / \mathrm{s} \Delta \mathrm{V}$ for NSSK and EWSK maneuver. Satellite orbital maneuver NSSK accumulated $\Delta \mathrm{V}$ of $975.84 \mathrm{~m} / \mathrm{s}$ makes 20.0 year satellite lifetime from Figure 4 (a) and Figure 4 (b).

The summary of the above-mentioned steps is shown in Table 5 . Table 5 provides the necessary $\Delta \mathrm{V}$ of the proposed straightforward method for different launch weigts. In reverse, the propellant budget and associated maneuver life can be calculated by applying the method.

Table 5 Sat-A maneuver life calculation using the proposed straightforward method

\begin{tabular}{|c|c|c|c|c|c|}
\hline & $\Delta V(\mathrm{~m} / \mathrm{s})$ & $\mathbf{I}_{\mathrm{sp}}(\mathrm{s})$ & Efficiency & \begin{tabular}{|l|}
$\begin{array}{l}\text { Consumed } \\
\text { propellant(kg) }\end{array}$ \\
\end{tabular} & \begin{tabular}{|l} 
Resulting weight \\
(kg)
\end{tabular} \\
\hline \multicolumn{5}{|l|}{ Satellite total mass $(\mathrm{kg})$} & 3500,00 \\
\hline GTO to GEO & 1470.10 & 321 & $94.00 \%$ & 1370.37 & 2129.63 \\
\hline EWSK & 36.80 & 288 & $90.00 \%$ & 30.61 & 2099.02 \\
\hline Orbital relocation & 5.68 & 288 & $85.00 \%$ & 4.96 & 2094.06 \\
\hline \multicolumn{2}{|l|}{ Attitude control, wheel unloading } & 288 & $85.00 \%$ & 9.57 & 2084.48 \\
\hline NSSK & 975.84 & 291 & $91.00 \%$ & 652.95 & 1431.54 \\
\hline De-orbiting & 12.76 & 288 & $85.00 \%$ & 7.59 & 1423.95 \\
\hline \multirow{2}{*}{\multicolumn{5}{|c|}{\begin{tabular}{l|r} 
& 23.95 \\
Satellite dry mass $(\mathrm{kg})$
\end{tabular}}} & 1400.00 \\
\hline & & & & & 1400.00 \\
\hline
\end{tabular}

Falcon 9 and Proton launch vehicle performances are different fromAriane 5 so the maneuver lifetime shown on the table 5 is subject to change. Similarly, the proposed method provides the propellant budget shown in Table 6 for 30 years maneuver life satellite.

Table 6 Sat-B maneuver life calculation using the proposed straightforward method

\begin{tabular}{|c|c|c|c|c|c|}
\hline & $\Delta V(\mathrm{~m} / \mathrm{s})$ & Isp (s) & Efficiency & $\begin{array}{l}\text { Consumed } \\
\text { propellant (kg) }\end{array}$ & $\begin{array}{l}\text { Resulting weight } \\
\text { (kg) }\end{array}$ \\
\hline \multicolumn{5}{|c|}{ Satellite total mass $(\mathrm{kg})$} & 4800,00 \\
\hline GTO to GEO & 1470.10 & 321 & $94.00 \%$ & 1879.37 & 2920.63 \\
\hline EWSK & 55.20 & 288 & $90.00 \%$ & 62.74 & 2857.89 \\
\hline Orbital relocation & 5.68 & 288 & $85.00 \%$ & 6.75 & 2851.14 \\
\hline \multicolumn{2}{|c|}{ Attitude control, wheel unloading } & 288 & $85.00 \%$ & 19.53 & 2831.61 \\
\hline NSSK & 1461.30 & 291 & $91.00 \%$ & 1218.55 & 1613.06 \\
\hline De-orbiting & 12.76 & 288 & $85.00 \%$ & 8.55 & 1604.51 \\
\hline \multicolumn{4}{|c|}{ Propellant residuals and $\mathrm{He}$} & 34.51 & 1570.00 \\
\hline \multicolumn{5}{|c|}{ Satellite dry mass (kg) } & 1570.00 \\
\hline
\end{tabular}


The above algorithm is a straightforward approach and provides useful results to estimate the maneuver life of a satellite. However, if the satellite operators need more accurate remaining propellant information, then the situation becomes complex, and some error sources associated with input parameters must be considered.

The uncertainties from dispersions should be taken into account for a more accurate propellant budget. Table 7 summarizes the dispersions and their translation into the equivalent $\Delta \mathrm{V}$ associated with the $\mathrm{I}_{\mathrm{sp}}$ and efficiency.

Table 7 Sat-A and Sat-B dispersion calculation based on satellite and equipment manufacturer data

\begin{tabular}{|l|c|c|c|c|c|}
\hline \multicolumn{1}{|c|}{ Dispersions } & $\Delta \mathrm{V} \mathrm{(m/s)}$ & $\mathbf{I}$ sp (sec) & Efficiency & $\begin{array}{c}\mathbf{2 0} \text { year } \Delta \mathrm{V} \\
(\mathbf{m} / \mathbf{s})\end{array}$ & $\begin{array}{c}\mathbf{3 0} \text { year } \Delta \mathrm{V} \\
(\mathbf{m} / \mathbf{s})\end{array}$ \\
\hline Launch dispersions corrected with ABM & 0.524 & 321.00 & 0.993 & 0.470 & 0.470 \\
\hline Launch dispersions corrected with Thruster & 4.321 & 288.00 & 0.860 & 4.990 & 4.990 \\
\hline AKE pointing & 4.147 & 321.00 & 0.993 & 3.721 & 3.721 \\
\hline AKE thrust level & 0.104 & 321.00 & 0.993 & 0.093 & 0.093 \\
\hline AKE specific impulse & 4.665 & 321.00 & 0.993 & 4.186 & 4.186 \\
\hline Thruster pointing & 0.648 & 286.00 & 0.920 & 0.844 & 1.312 \\
\hline Thruster Isp specific impulse & 9.190 & 286.00 & 0.920 & 11.975 & 18.613 \\
\hline Impact of N/S control on orbit longitude & 7.287 & 286.00 & 0.860 & 10.157 & 15.789 \\
\hline Attitude control uncertainty & & 5.821 & 9.048 \\
\hline Residuals uncertainty (mixture ratio) & & 30.079 & 41.219 \\
\hline \multicolumn{7}{|l|}{ Total (RSS) m/s } & & & 35.247 & 49.34 \\
\hline Total (RSS) kg & & 18.912 & 30.08 \\
\hline
\end{tabular}

Communication satellite detailed propellant budget can be calculated by using the same equations, but more detailed parameters should be taken into account as shown in Table 8 . Table 8 provides propellant budget details of Sat-A communication satellite. In this case, 20.413 year maneuver life is calculated. There is some increase in maneuver life, but this does not mean that the detailed calculations always provide higher results.

Table 8 Sat-A maneuver life calculation considering uncertainties

\begin{tabular}{|c|c|c|c|c|c|}
\hline Maneuvers & $\begin{array}{l}\Delta V \\
(\mathrm{~m} / \mathrm{sec})\end{array}$ & Isp & Efficiency & $\begin{array}{c}\text { Consumed } \\
\text { Propellant (kg) }\end{array}$ & \begin{tabular}{|c} 
Resulting weight \\
(kg)
\end{tabular} \\
\hline \multicolumn{5}{|l|}{ Satellite total mass $(\mathrm{kg})$} & $\begin{array}{r}3500.00 \\
\end{array}$ \\
\hline \multicolumn{4}{|l|}{ Transfer orbit attitude control } & 3.00 & 3497.00 \\
\hline AKE 1 & 570.00 & 320.95 & 99.40 & 582.46 & 2914.54 \\
\hline AKE 2 & 794.20 & 320.95 & 99.30 & 654.01 & 2260.54 \\
\hline AKE 3 & 105.90 & 320.95 & 99.50 & 75.16 & 2185.37 \\
\hline Post-apogee maneuver & 4.00 & 289.35 & 85.00 & 3.62 & 2181.75 \\
\hline IOT reposition. Maneuver & 5.68 & 289.35 & 85.00 & 5.13 & 2176.62 \\
\hline \multicolumn{2}{|l|}{ Attitude and wheel unloading: 1} & 288 & 90 & 4.70 & 2171.92 \\
\hline NSSK & 1013.14 & 291.50 & 91.10 & 699.99 & 1471.93 \\
\hline EWSK & 36.40 & 278.50 & 90.20 & 21.59 & 1450.34 \\
\hline Attitude and wheel unloading: 2 & 5.5 & 290 & 100 & 2.80 & 1447.54 \\
\hline Station repositioning & 5.680 & 289.35 & 90.20 & 3.21 & 1444.33 \\
\hline On-orbit raising & 12.760 & 288.10 & 90.20 & 7.21 & 1437.11 \\
\hline Dispersion corrections & 35.050 & 282.00 & 100.0 & 18.10 & 1419.01 \\
\hline \multicolumn{2}{|l|}{ Propellant residual } & 285 & 100 & 14.81 & 1404.20 \\
\hline \multicolumn{4}{|l|}{ Pressurant (Helium) } & 4.20 & \\
\hline \multicolumn{5}{|c|}{ Satellite dry mass (kg) } & 1400.00 \\
\hline
\end{tabular}

Communication satellite Sat-B, detailed propellant analysis, is shown in Table 9. Table 9 provides a detailed lifetime analysis. Orbit raising details, $I_{s p}$, and efficiency of the thrusters are taken into account 
more realistically. The result is more accurate than the straightforward method. However, the difference is only $1 \%$.

Table 9 Sat-B maneuver life calculation considering uncertainties

\begin{tabular}{|c|c|c|c|c|c|}
\hline Maneuvers & $\begin{array}{l}\Delta \mathbf{V} \\
(\mathbf{m} / \mathbf{s e c})\end{array}$ & Isp & Efficiency & $\begin{array}{c}\text { Consumed } \\
\text { Propellant (kg) }\end{array}$ & $\begin{array}{l}\text { Resulting weight } \\
\text { (kg) }\end{array}$ \\
\hline \multicolumn{5}{|l|}{ Satellite total mass $(\mathrm{kg})$} & 4800.00 \\
\hline \multicolumn{4}{|l|}{ Transfer orbit att. } & 3.00 & 4797.00 \\
\hline AKE 1 & 570.00 & 320.95 & 99.40 & 798.98 & 3.998 .02 \\
\hline AKE 2 & 794.20 & 320.95 & 99.30 & 897.13 & 3.100 .89 \\
\hline AKE 3 & 105.90 & 320.95 & 99.50 & 103.10 & 2.997 .78 \\
\hline Post-apogee maneuver & 4.00 & 289.35 & 85.00 & 4.97 & 2.992 .81 \\
\hline IOT reposition maneuver & 5.68 & 289.35 & 85.00 & 7.04 & 2.985 .77 \\
\hline \multicolumn{2}{|l|}{ Attitude and wheel unloading: 1} & 288 & 90 & 8.80 & 2976.98 \\
\hline NSKK & 1.485 .73 & 291.50 & 91.10 & 1294.27 & 1682.70 \\
\hline EWSK & 54.60 & 278.50 & 90.20 & 36.88 & 1645.82 \\
\hline Attitude and wheel unloading: 2 & 8 & 290 & 100 & 4.62 & 1641.20 \\
\hline Station repositioning & 5.680 & 289.35 & 90.20 & 3.64 & 1637.56 \\
\hline On-orbit raising & 12.760 & 288.10 & 90.20 & 8.18 & 1629.38 \\
\hline Dispersion corrections & 49.340 & 282.00 & 100.0 & 28.81 & 1600.57 \\
\hline Propellant residual & 45.000 & 285 & 100 & 25.56 & 1575.00 \\
\hline \multicolumn{4}{|l|}{ Pressurant (Helium) } & 5.00 & \\
\hline \multicolumn{5}{|c|}{ Satellite dry mass (kg) } & 1570.00 \\
\hline
\end{tabular}

The proposed method provides enough accuracy to estimate maneuver life based on the propellant budget. The accuracy of the remaining propellant at the end of life is calculated using three methods. PVT method provides $\pm 27.3 \mathrm{~kg}$ and $\pm 38.93 \mathrm{~kg}$ remaining propellant for Sat-A and Sat-B respectively. BK method remaining propellant estimation is $\pm 9.83 \mathrm{~kg}$ and $\pm 13.76 \mathrm{~kg}$, and TPG remaing propellant assessment is \pm 10.52 and \pm 14.73 .85 for Sat-A and Sat-B. Due to the high uncertainty of the PVT method, it cannot reliably be used for the EOL determination. Instead, it will be used in comparison with the pulse counting method to detect any anomaly. The accuracy analysis shows that the propagation of uncertainties is related to the propellant load, system design, ground filling, orbital operations, and applied sensors. It was found that BK currently provides the highest gauging accuracy, as shown in Table 10.

Table 10 Sat-A and Sat-B remaining propellant estimation for three gauging methods and associated IGSO maneuver life

\begin{tabular}{|l|c|c|}
\hline \multirow{2}{*}{\multicolumn{1}{|c|}{ Methods }} & \multicolumn{2}{c|}{ Remaining propellant (kg) } \\
\cline { 2 - 3 } & Sat-A & Sat-B \\
\hline PVT method & \pm 27.81 & \pm 38.93 \\
\hline Bookkeeping method & \pm 9.83 & \pm 13.76 \\
\hline Thermal Propellant Gauging method & \pm 10.52 & \pm 14.73 \\
\hline
\end{tabular}

The proposed methods can calculate a propellant budget from a required maneuver life. However, the satellite operators need a more accurate remaining propellant amount, especially close to satellite EOL. The most common three methods are discussed, and their performances are evaluated. The BK provides the best results currently, and TPG is the second accurate method. PVT provides coarse results and can be utilized for checking purposes. The results are based on typical communication satellite system data and equipment characteristics. Changes in system design and equipment characteristics affect the estimated accuracy of the methods. The satellite operators request to improve the gauging accuracy up to \pm 1 months for new satellites. This goal can be achieved with significant improvement of the system design and analysis, ground operations, and in-flight sensor technology. 


\section{Acknowledgments}

I would like to thank Turksat AS for its invaluable support.

\section{References}

[1] R. C. Benthem et al., “ Accuracy analysis of propellant gauging systems”, 43rd International Conference on Environmental Systems, pp. 3300, 2013.

[2] R. Nariyoshi, S. Chernikov, and B. S.Yendler, "Prediction of Spacecraft Remaining LifeChallenges and Achievements", 49th AIAA/ASME/SAE/ASEE Joint Propulsion Conference, pp. 4162, 2013.

[3] J. W. Eun, “A Study on Fuel Estimation Algorithms for a Geostationary Communication \& Broadcasting Satellite”, Journal of Astronomy and Space Sciences, 17(2), pp.249-256., 2000.

[4] B. S. Yendler, M. Myers, N. Chilelli, S. Chernikov, J. Wang, A. Djamshidpour, "Implementation of Thermal Gauging Method for ABS 1A (LM 3000) satellite", 14th International Conference on Space Operations, (p. 2458)., 2016.

[5] B. S. Yendler, J. Molinsky, S. Chernikov, D. Guadagnoli, "Comparison of gauging methods for Orbital's GEOStarTM 1 Satellites”, SpaceOps 2014 Conference, pp.1810, 2014.

[6] B. Yendler, "Review of propellant gauging methods", 44th AIAA aerospace sciences meeting and exhibit, p. 939, 2006.

[7] I. Oz, L. Pelenc, B. Yendler, “Thermal Propellant Gauging, SpaceBus 2000 (Turksat 1C) Implementation”, AIAA 2008-7697, San Diego, California, pp.7697, 2008.

[8] I. Oz and Ü. C. Y1lmaz, "Determination of Coverage Oscillation for Inclined Communication Satellite”, Sakarya Üniversitesi Fen Bilimleri Enstitüsü Dergisi, 24(5), pp. 963-973., 2020.

[9] B. Cabrières, F. Alby, C. Cazaux, "Satellite end of life constraints: Technical and organisational solutions”, Acta Astronautica, vol.73, pp. 212-220, 2012.

[10] J. Fu, X. Chen, , Y. Huang, "Uncertainty Analysis of Propellant Compression Mass Gauge for Spacecraft”, Procedia Engineering, 31, pp.122-127, 2012.

[11] S. Côté, S., K. Srivastava, P. Le Dantec, R. Hawkins, K. Murnaghan,” Anik E Spacecraft Life Extension”, Space OPS 2004 Conference, pp. 208., 2004.

[12] A. Aparicio, B. Yendler, “Thermal propellant gauging at EOL, Telstar 11 implementation”, SpaceOps 2008 Conference, pp. 3375, 2008.

[13] W. Yin, Z. Cao, Z. Lin, "Research on Combination of Multiple Methods for Spacecraft Propellant Consumption Prediction”, IOP Conference Series: Materials Science and Engineering, Vol. 887, No. 1, pp. 012039 IOP Publishing., 2020.

[14] A. Lal, B. N. Raghunandan, "Uncertainty analysis of propellant gauging system for spacecraft”, Journal of Spacecraft and Rockets, 42(5), pp. 943-946., 2005.

[15] E. M Soop, W. R. Burke, “Introduction to geostationary orbits”, STIN, 84, 21590., 1983.

[16] A. Grise, T. Douglas, "Maximization of satellite lifetime: Telesat Canada's experience”, SpaceOps 2006 Conference, pp. 5906, 2006. 